Article

\title{
Close-to-Application Test Methodology Validated by a Baseline Study for Novel Bearing Developments in Aircraft Turbines
}

\author{
Philipp Renhart ${ }^{1, *(\mathbb{D}}$, Florian Summer ${ }^{1}\left(\mathbb{D}\right.$, Florian Grün ${ }^{1}(\mathbb{D})$ and Andreas Eder ${ }^{2}$ \\ 1 Department Product Engineering, Montanuniversität Leoben, Franz-Josef-Straße 18, 8700 Leoben, Austria; \\ florian.summer@unileoben.ac.at (F.S.); florian.gruen@unileoben.ac.at (F.G.) \\ 2 High Tech Coatings GmbH, Dr.-Mitterbauer-Str. 3, 4655 Vorchdorf, Austria; andreas.eder2@miba.com \\ * Correspondence: philipp.renhart@unileoben.ac.at; Tel.: +43-3842-402-1464
}

Received: 28 November 2019; Accepted: 24 December 2019; Published: 9 January 2020

\begin{abstract}
The main objective of the present paper is the validation of new methods concerning experimental investigations of journal bearings under ordinary and extraordinary operational conditions. Derived results should facilitate the determination of damage mechanisms and a qualitative ranking for a prospective coating development. Prior investigated scenarios like start/stop and emergency running behavior were extended by starved and unlubricated experiments for an aircraft application. Focusing on thermal stability and reproducibility, two new subscale test strategies were developed derived from generalized operational conditions of journal bearings. For an improved ex-situ wear measurement of bearing shells, a new device was developed successfully. The results showed that the newly designed test methodologies are suitable to investigate unlubricated coatings leading to conclusive and repetitive results.
\end{abstract}

Keywords: coatings; bearing; testing; sub-scale; methodology

\section{Introduction}

Current developments in aircraft engines tend towards significant reduction emission of $\mathrm{CO}_{2}$, $\mathrm{NO}_{x}, \mathrm{SO}_{\mathrm{x}}$, and noise pollution [1,2]. A promising approach to improve efficiency and reduce emissions simultaneously is the so-called geared turbofan resulting in a very high bypass-ratio (VHBR) of the fan. The gearbox facilitates the low-pressure turbine to operate at higher speed compared to the fan, which increases the efficiency [3], facing the optimization of the fan's air flow and thermodynamic behavior.

Typically, journal bearings are designed to operate in a nearly wear-free hydrodynamic condition [4], wear occurs primary in solid-friction a mixed-friction states [5]. Investigations focusing on the Start/Stop behavior of various bearing materials and coatings with Zincdialkyldithiophosphate (ZDDP) additivated automotive engine oils were performed earlier by Summer et al. [6,7].

The emergency running behavior of the casted lining material $\mathrm{CuPb} 22 \mathrm{Sn}$ coated with $\mathrm{PbSn} 18 \mathrm{Cu} 2$ (electroplated) and polymeric overlay (sprayed) was investigated earlier by Grün et al. [8]. He pointed out a significant improvement of emergency running capabilities for the $\mathrm{PbSn} 18 \mathrm{Cu} 2$ coating and an improvement of the loading capacity with the polymeric coating in comparison to the bare lining material.

Research on lead-free $\mathrm{Cu} / \mathrm{Al}$-based lining materials amongst others polymeric overlays (poly-amideimide (PAI), $\mathrm{MoS}_{2}$, graphite) and Sn-based coatings were performed earlier by Gebretsadik et al. $[9,10]$ using a block-on-ring test configuration lubricated with poly-alpha olefin synthetic base oil, respectively a fully formulated paraffin $10 \mathrm{~W}-30$ oil. 
Polymeric coatings containing self lubricating $\mathrm{MoS}_{2}$-particles were examined by Bergseth et al. [11] on a pin-on-disc test-rig under marginal lubrication, implying total dry-run and initial lubrication.

Since the arising of the start-stop technology in the automotive sector, reinforced PAI with embedded solid lubricants are a tried-and-tested protection against wear [12].

This literature-extract shows that journal bearings and their testing methods are strongly coupled to automotive requirements. Reliability and ensured safety during the operating lifetime of aircraft turbines is obviously the primary objective for developments in this area. This requires tailored test programs to embrace different potentially dangerous damage sources with a particular focus on unlubricated situations due to non-existent journal bearing tests. Considering multiple conceivable scenarios test strategies were designed covering starting-up and running-down of the turbine, dry-run conditions at low loads and emergency-running behavior at different points of the Stribeck curve.

\section{Methodology}

In the following section, an overview of test programs, the specimens, the utilized set-up, and applied test methods is given.

\subsection{Test Rigs}

Within this work, two test-rigs were used, the bearing-segment tester (BST) depicted in Figure 1a built-in on a TE92HS and a ring-on-disc (ROD) set-up on a TE92 as shown in Figure 1b. Both rotary tribometers were produced by Phoenix Tribology Ltd. (Basingstoke, UK).

a)

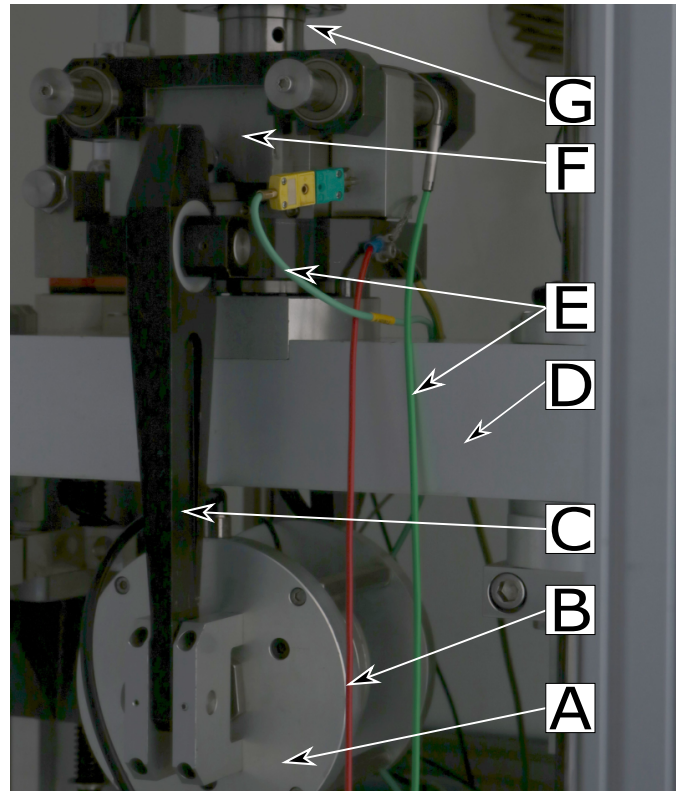

b)

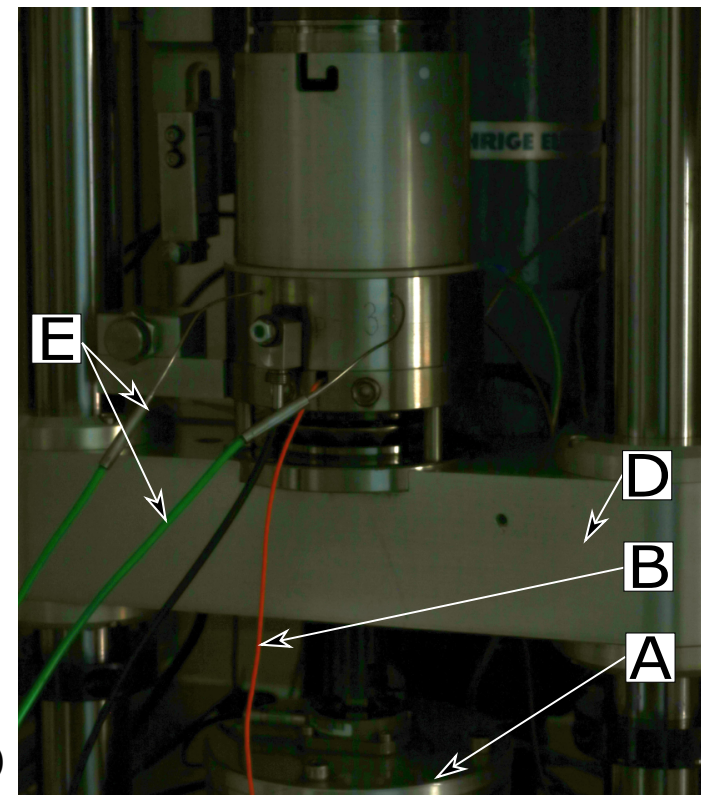

Figure 1. Components of the bearing segment tester(a) and the ring-on-disc setup (b): Bellows cylinder (A), Contact Potential measurement (B), lever arm (C), support (D), temperature sensor (E), segment adapter $(\mathrm{F})$, and the shaft $(\mathrm{G})$.

\section{Bearing Segment Tester}

The working principle of the BST is a rotating shaft in between two symmetrically arranged $120^{\circ}$ radial bearing segments with a diameter of $47.6 \mathrm{~mm}$ and a width of $6 \mathrm{~mm}$. The diameter of the corresponding shaft was customized for a predefined bearing clearance of $1.6 \%$. Both segments are mounted in adapters which are loaded by a pneumatic cylinder by means of levers. The torque transmission between the top driven shaft and the freely rotatable supported bearing segments represents the frictional moment of both segments. Assuming an ideal ball bearing of the support with the known radial force and geometry, the coefficient of friction $\mu(\mathrm{COF})$ is measurable. All parts of the 
tribological system (shaft and both segments) are fully immersed in a temperature-controlled oil basin. The temperature of the segment is recordable up to $250{ }^{\circ} \mathrm{C}$ on its steel back and in the oil reservoir. Due to geometric properties, the BST is capable of operating in the hydrodynamic state where the full range of the Stribeck's curve is testable.

\subsection{Ex-Situ Wear Measurement}

The target for the development of a new device was the demand for a further increase of the repetitive accuracy in thickness measurements of bearing layers. Several measuring points are deterministic distributed on the circularly shaped specimen. Since the wear is metered before and after the experiment by relative changes on these specific measuring points, a highly repeatable position accuracy is mandatory for precise results. The new device (see Figure $2 a$ ) for wear measurement is based on a pivoted digital indicator with an absolute scale. For this set-up, a digital indicator MarCator $1087 \mathrm{R}$ from Mahr GmBH (Esslingen, Germany) with a measuring range of $12.5 \mathrm{~mm}$ was used, and the tip radius of the dial is $1.5 \mathrm{~mm}$ with a measuring force between $0.65 \mathrm{~N}$ to $0.9 \mathrm{~N}$. In Figure $2 \mathrm{~b}$, all of the main components are shown. On the backside of the rotatable fixture of the indicator, the angular position is readable on an analogue scale. The vertical adjustment of the measuring position is provided by precisely machined disks with different heights.

In this work, all bearing segments were measured at 21 positions (three specific heights and seven angular positions). Expecting a majority of the total wear in the middle of the segment, the angular positions were defined denser in this area. For the determination of the relative mass lost within an experiment, a high precision scale (Sartorius, CP 255 D-OCE, Goettingen, Germany) was used. As the manufactured radius of each fixture is known precisely, the real bearing clearance $\Psi$ of every single specimen can be evaluated. Assuming full contact between the steel back of the bearing and the fixture, the bearing radius $R$ is the sum of the manufactured radius $R_{M}$ and the the thickness of the bearing $S$. The radius of the shaft $R_{S}$ can be used to compensate thickness deviations in the bearing manufacturing process:

$$
\Psi=\frac{R_{M}+S-R_{S}}{R_{S}} .
$$
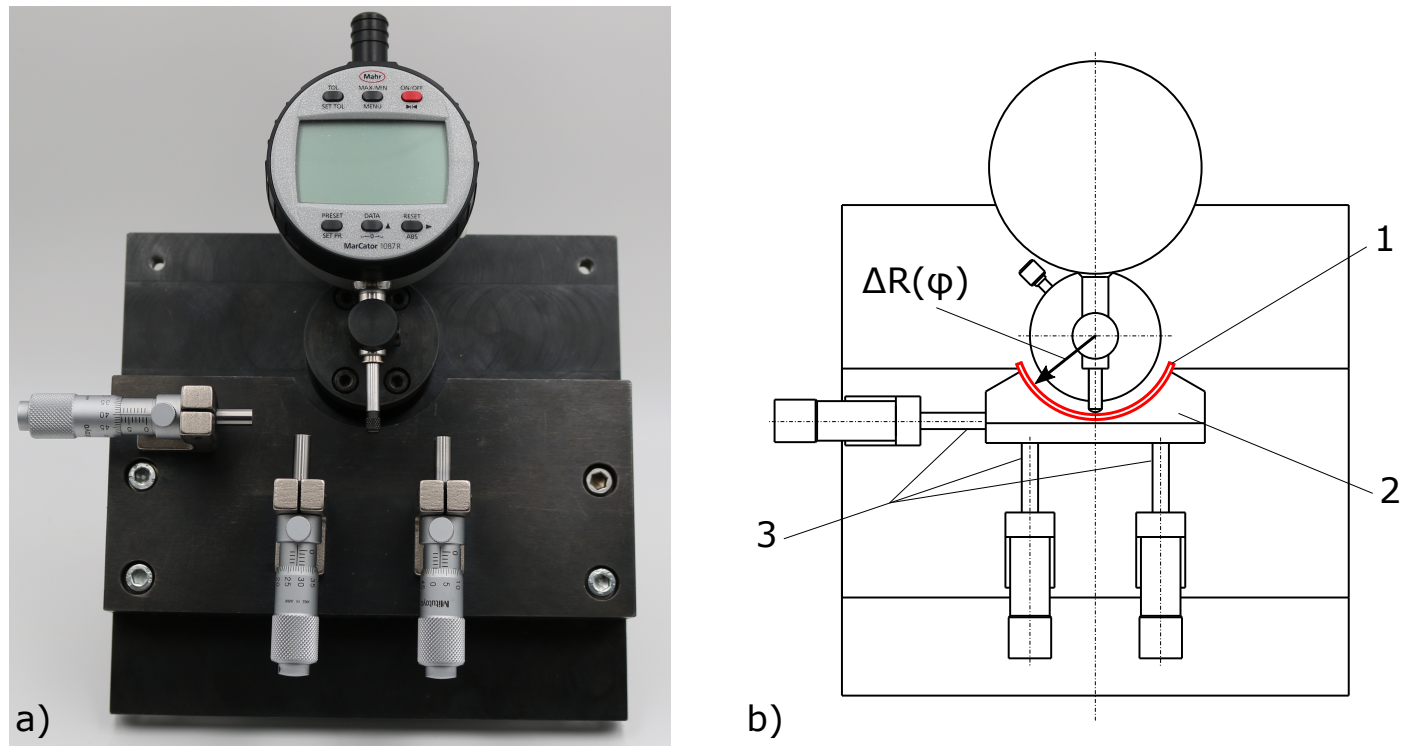

b)

Figure 2. Developed wear measurement device. Built up device without specimen (a), main components of the device (b). Bearing-Segment (1), fixture (2), micrometer gauges for adjustment (3). 


\section{Ring on Disc Set Up}

For experimental investigations, intentionally without hydrodynamic influence, the ROD set-up on the TE92 is applicable. A disc and a ring with plain surfaces are rotating relative to each other, whereby the fixed part of the tribological system, in this case the ring specimen, represents the material of the shaft and the composition of the disc is equal to the journal bearing. Experimental parameters of this set up are the nominal pressure $(p, \mathrm{MPa})$, the rotational speed $(n, \mathrm{rpm})$, and the oil temperature $\left(T,{ }^{\circ} \mathrm{C}\right)$ of the basin. The instrumentation of this configuration includes thermocouples in the basin and close to the contacting surfaces, a displacement sensor, and the measurement of the contact resistance. The measuring principle of the COF is identical to that on the BST. The fixed ring includes thermocouples for controlling and recording up to $250^{\circ} \mathrm{C}$. Additionally, an acoustic emission sensor (Type 8152C0000320, Kistler Group, Winterthur, Switzerland) is attached to the basin for a deeper insight to certain events. However, in order to protect the set up, general termination criteria are defined for all test programs. The maximal COF is generally defined to be $\mu=0.3$ and the top temperature is set to a value of $150{ }^{\circ} \mathrm{C}$.

\subsection{Test Programs}

The Start-Stop-test (SST) obviously describes the cyclic degradation of the journal bearing (JBGR) due to starting up and running down over the entire lifetime. The SSTs were performed at constant loads and temperatures, whereby the relative speed cycles are set between zero and $1.27 \mathrm{~m} / \mathrm{s}$ after a defined heating of the system. Collectively, 9000 Stribeck cycles are recorded with a measuring rate of $10 \mathrm{~Hz}$; in addition, every hundredth cycle is recorded at $1 \mathrm{kHz}$. This enables a detailed investigation of the continuously varying Stribeck's curve. A schematic overview of the SST test program is given in Figure 3a.

The Oil-starvation-test (OST) represents mixed-friction states superimposed with high bearing loads. The basic idea for this experiment was the total removal of the lubricant after a defined running-in phase. Figure $3 \mathrm{~b}$ depicts the constant parameters' temperature, speed, and load during the experiment. The running-in process of the OST and the SST is identical and fully lubricated to ensure the same starting conditions.

a)

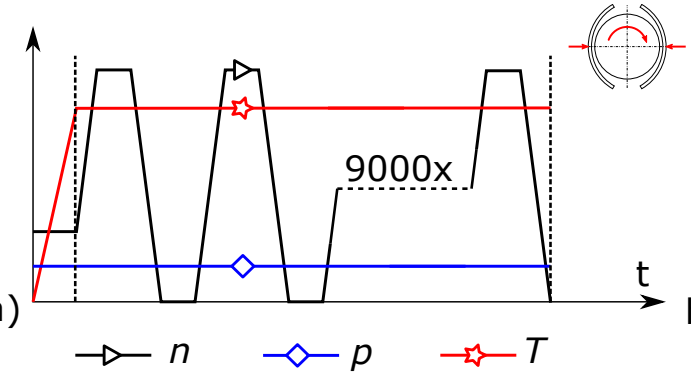

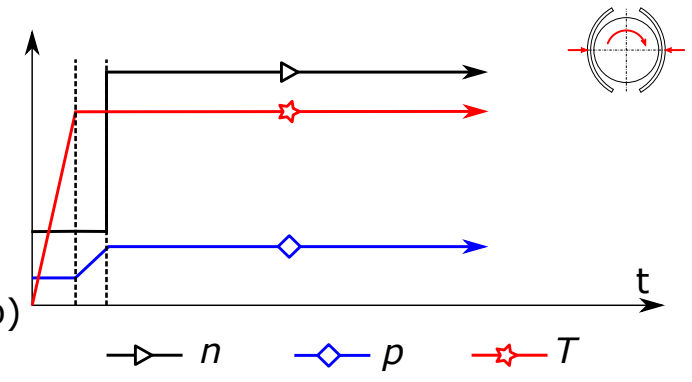

Figure 3. Overview of the test program carried out with the BST system: Start-Stop-test (a) and Oil-Starvation-test $(\mathbf{b})$. The controlled test parameters rotational speed $n$, nominal pressure $p$, and the oil temperature $T$ are shown.

An approach to characterize the emergency running properties and to determine the seizure limit of a tribological system is the seizure-test (ST), whereby the speed and the temperature is held at a constant level superimposed with a stepwise increased mechanical load. The test ends at predefined termination criteria indicate a major seizure event and the consequential failure of the tested specimen. During the entire test, the ring and the rotating disc are fully submerged in oil. A schematic overview of the mechanical and thermal loads are given in Figure 4a.

The Dry-Run-test (DRT) imitates thermal stable conditions where bearings are only lightly loaded without active lubrication; see Figure $4 \mathrm{~b}$. The duration of the test is limited to 10 hours. In contrast to the fully lubricated seizure test, only the surface of the fixed specimen (ring) is initially wetted with oil. 
To ensure a consistent amount of lubricant, four self-detaching drops were spread on the ring before the test was started. Furthermore, the used cannula was weighted before and after the procedure.

a)

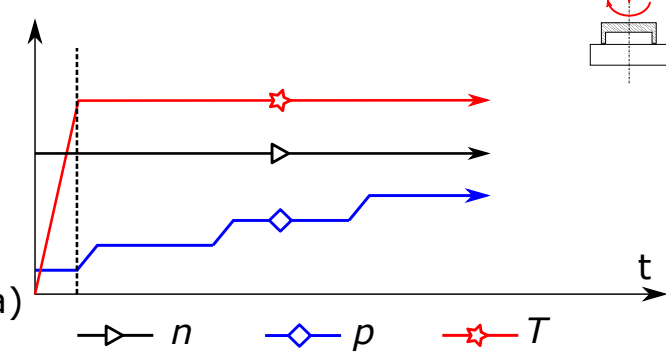

b)

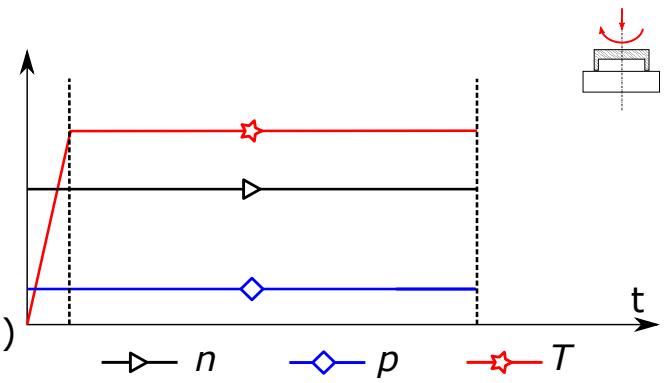

Figure 4. Overview of the test program carried out with the ring-on-disc (ROD) set-up: Seizure-test (a) and the Dry-Run-test $(\mathbf{b})$. The controlled test parameters rotational speed $n$, nominal pressure $p$ and the oil temperature $T$ are shown.

Since the DRT is explicitly stated to operate at a constant temperature level, the oil basin was filled partially with oil to ensure a sufficient heat transition between the test rig, thermocouples, and the fixed specimen. The oil quantity was chosen so that the lubricant is covering all thermocouples and a filling level below the contacting zone. In Figure 5, the previously described configuration is visualized.

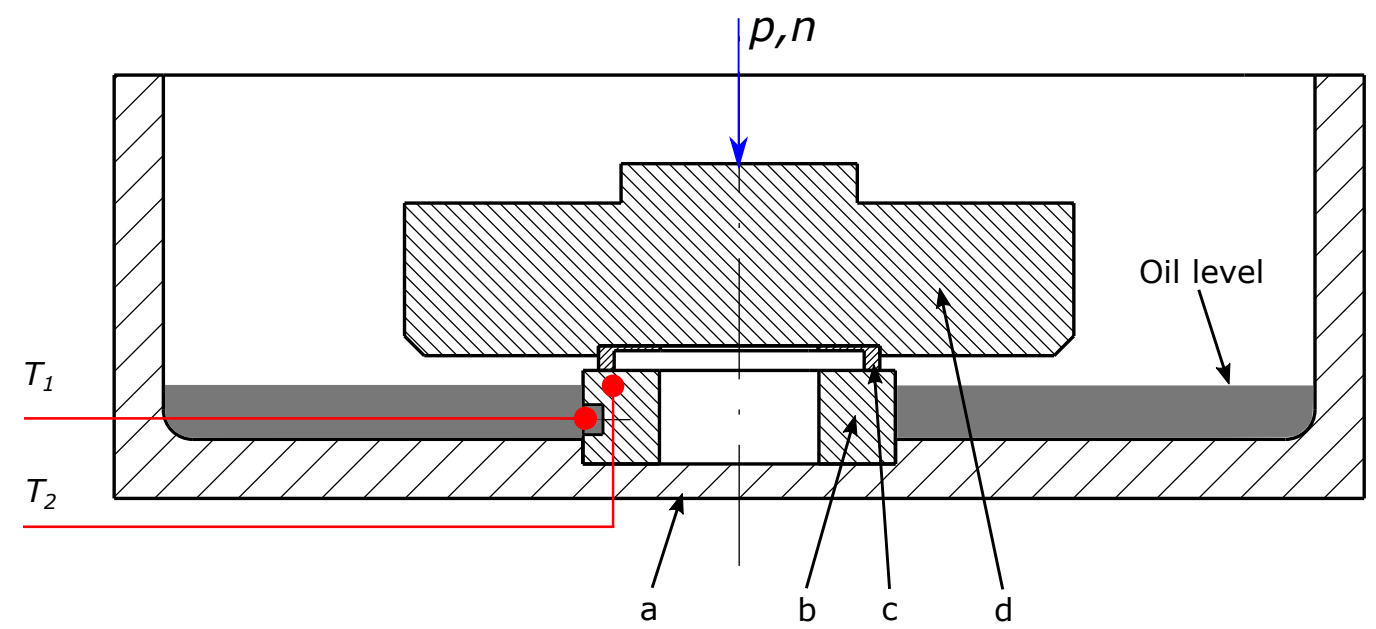

Figure 5. Configuration of the ROD test-rig for a Dry-run test. The housing of the oil bath (a), the fixed specimen (b), the rotating disc (c), and the driven specimen holder of the set-up (d). The controlled test parameters' rotational speed $n$, nominal pressure $p$, and the oil temperature $T_{1}$ are shown. Additionally, the position of the contact-near thermocouple $T_{2}$ is shown.

\subsection{Materials}

All tests were performed with the same lubricant, which is a widespread used turbine oil containing tricresylphosphate (TCP) with a kinematic viscosity of $5.3 \mathrm{~mm}^{2} / \mathrm{s}$ at $100{ }^{\circ} \mathrm{C}$. The steel specimen, representing the shaft of the investigated bearing system, was a quenched and tempered steel $34 \mathrm{CrNiMo} 4$. For this work, different tribological systems were tested, and an overview of the investigated materials, coatings, and corresponding test programs is given in Table 1 . The investigated bearing materials are bi- and trimetal systems on a steel back with identical external geometries. The examined tribological systems are tin and lead based state-of-the-art journal bearing materials with excellent wear-resistance and emergency-running properties. 
Table 1. Investigated bearing materials, coatings and corresponding test programs.

\begin{tabular}{clllll}
\hline Specimen Geometry & Lining Material & Coating & Thickness, $\mu \mathbf{m}$ & Test Program & Performed Tests \\
\hline ROD & CuPb22Sn2 & Polymer & 17 & DRT & 5 \\
ROD & CuPb22Sn2 & SnCuSbNi & 16 & ST & 7 \\
ROD & CuPb22Sn2 & uncoated & n.a & ST & 5 \\
BST & CuPb22Sn2 & PbSn18Cu2 & 16 & OST and SST & 4 and 5 \\
BST & CuPb22Sn2 & Polymer & 16 & OST and SST & 5 and 7 \\
\hline
\end{tabular}

The initial state of a $\mathrm{CuPb} 22 \mathrm{Sn} 2$ specimen spray-coated with a polymeric layer of $17 \mu \mathrm{m}$ thickness is shown in Figure 6a. The poly-amide-imide (PAI) matrix embeds particles of molybdenum disulfide $\left(\mathrm{MoS}_{2}\right)$ as a solid lubricant, graphite, and Ti-based hard particles as anti wear substances. As this coating has shown an excellent wear performance in mixed friction with automotive lubricants, test programs focusing wear behavior (DRT, OST and SST) were chosen. Figure $6 \mathrm{~b}$ shows the initial micro-structure of a SnCuSbNi coated $\mathrm{CuPb} 22 \mathrm{Sn} 2$ lining material. The soft matrix of the Sn-based coating prevents seizure during emergency-running situations, where this coating was tested with the ST program. The uncoated $\mathrm{CuPb} 22 \mathrm{Sn} 2$ lining material served as a direct reference. The lining material of the specimen depicted in Figure $6 \mathrm{c}$ is made of $\mathrm{CuPb} 22 \mathrm{Sn} 2$ with an PbSn18Cu2 electroplated coating (16 $\mu \mathrm{m}$ thickness) and a thin Ni-diffusion barrier in between. The real clearance of the used bearing segments was examined with the previously introduced measuring device resulting in negligible deviations.

a)

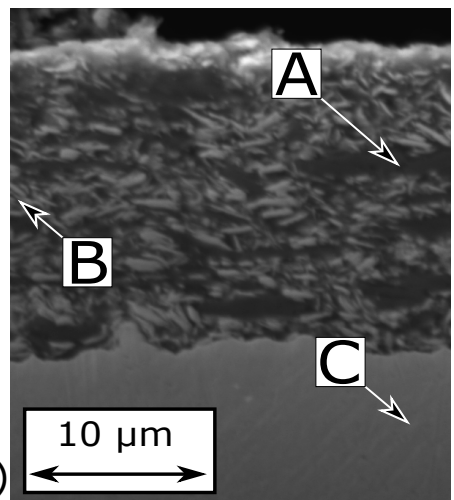

b)

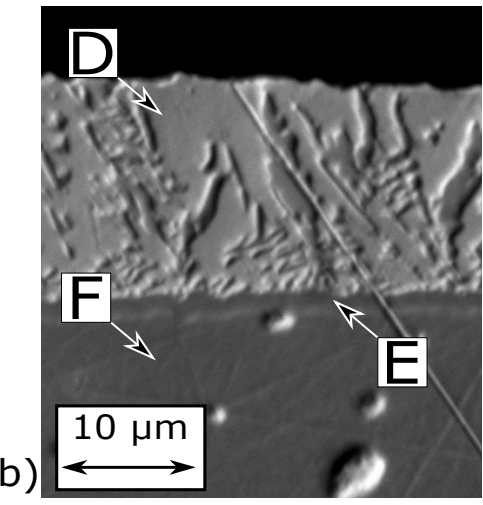

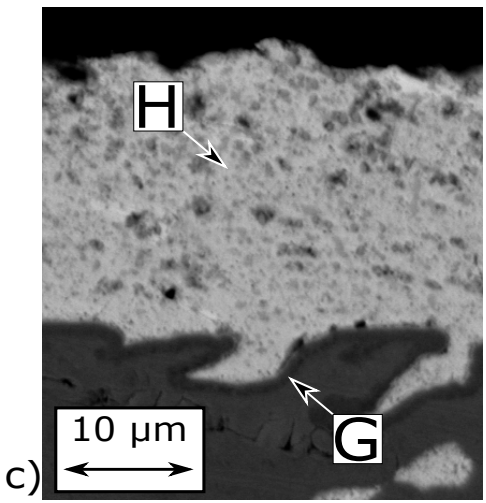

Figure 6. SEM/EDX (in Table 2) investigation of the top layers of coated bearing specimens before testing; polymeric coating (a); SnCuSbNi coating (b); and PbSn18Cu2 coating (c).

Table 2. Results of the EDX analysis obtained with an acceleration voltage of $7.5 \mathrm{kV}$, given in wt \%

\begin{tabular}{cccccccccc}
\hline Position & $\mathbf{C}$ & $\mathbf{O}$ & $\mathbf{S}$ & $\mathbf{T i}$ & $\mathbf{C u}$ & $\mathbf{M o}$ & $\mathbf{S n}$ & $\mathbf{N i}$ & $\mathbf{P b}$ \\
\hline A & 53.95 & 7.90 & 4.15 & 26.03 & - & 7.97 & - & - & - \\
B & 39.55 & 7.90 & 19.88 & 32.67 & - & - & - & - & - \\
C & 1.12 & - & - & - & 93.96 & - & 4.92 & - & - \\
D & - & - & - & - & - & - & 100 & - & - \\
E & 4.4 & - & - & - & - & - & - & 95.6 & - \\
F & 2.01 & - & - & - & 94.79 & - & 3.20 & - & - \\
G & 2.97 & - & - & - & 10.32 & - & 0.81 & 85.90 & - \\
H & 2.84 & 6.03 & - & - & 3.56 & - & 14.84 & - & 72.73 \\
\hline
\end{tabular}




\section{Results}

\subsection{Seizure Tests}

\subsubsection{Electroplated $\mathrm{SnCuSbNi}$}

The emergency running behavior of a CuPb22Sn2 lining material coated with $\mathrm{SnCuSbNi}$ is shown in Figure 7. During the heat ramp at the very beginning of the test, the COF is decreasing gradually due to changing oil viscosity and running-in of the mating surfaces. The running in process is not completely finished after reaching the steady state temperature of $100{ }^{\circ} \mathrm{C}$, the high contact potential (CP) and the still slightly decreasing COF can be seen as an indicator for this. Negative peaks in the CP signal like in Figure 7 mark A are minor seizure events as they typically occur after or during a load increase. At lower loads the tribological system is capable of compensating for these minor seizures as the restored CP indicates (point B). In point $\mathbf{C}$, the CP drops nearly to zero without considerable regeneration. This effect is most likely caused by fully aligned surfaces, which indicates a completed running-in process. From this point on, the behavior changes clearly, which can be seen by the continuously diverging temperature in the contact, a nearly constant wear rate, and the very low CP. In the further course of the test, the frictional behavior is slightly higher and accompanied by repeated peaks after increased loads. In point $\mathbf{E}$, the behavior changes rapidly observable by a fast increasing COF and temperature, caused by contacting the diffusion barrier and a consequential seizure event. The total thickness of the SnCuSbNi layer $(16 \mu \mathrm{m})$ and the differential height between $\mathbf{D}$ and $\mathbf{E}(19 \mu \mathrm{m})$ confirms this assumption. The test was aborted at $17 \mathrm{MPa}$ due reaching the temperature limit at $175^{\circ} \mathrm{C}$, point E). The total weight loss of this disc specimen was $46.41 \mathrm{mg}$, respectively $0.32 \mathrm{mg}$ on the steel ring.

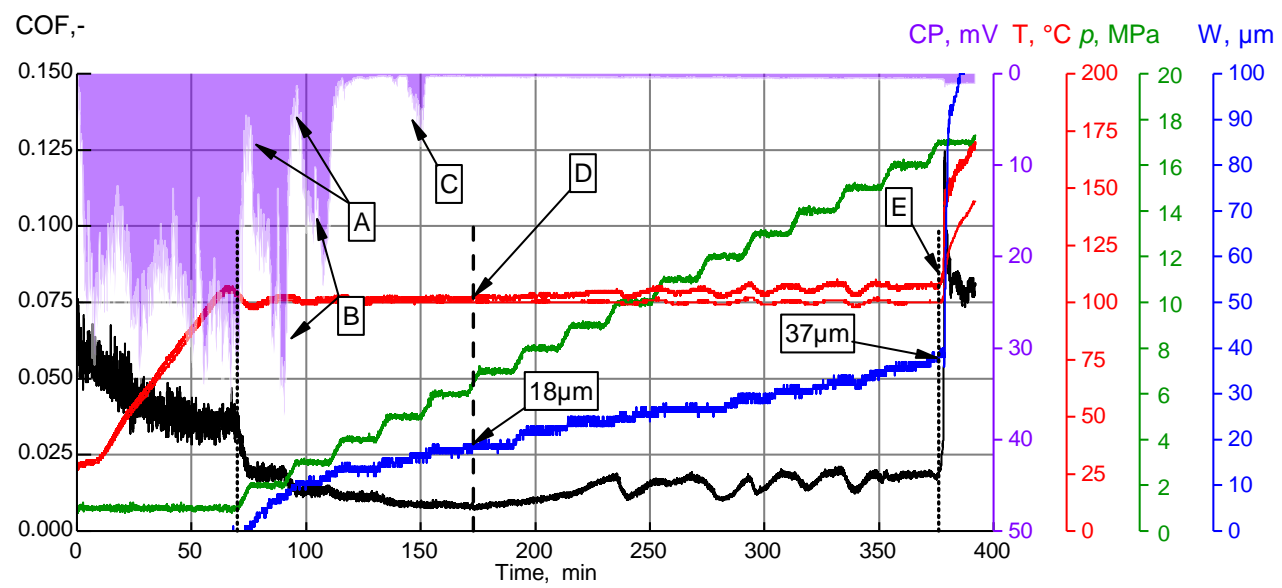

Figure 7. Result of a seizure test coated with $\mathrm{SnCuSbNi.} \mathrm{Minor} \mathrm{seizure} \mathrm{events} \mathrm{(A);} \mathrm{restoration} \mathrm{of}$ contact potential (CP) (B); seizure (C); thermal instabilities (D); test abortion (E).

\subsubsection{Uncoated Lining Material}

The performance of a casted lining material in a seizure test is shown in Figure 8. The frictional behavior is very similar to the SnCuSbNi coated specimen except for the absolute values of the COF. After the running in phase, the COF is decreasing continuously (see A) until the end of the test; minor peaks in COF are occurring typically during or after load ramps (see B). Overall, the CP is very low, which indicates a mixed friction over a large surface. Finally, the depicted test was aborted due to high temperatures in the contact induced by a seizure event. It must be mentioned that two of the tested specimens survived this experiment without a major seizure event, which is automatically stopped at $48 \mathrm{MPa}$. 
COF,-

$\mathrm{CP}, \mathrm{mV} \mathrm{T},{ }^{\circ} \mathrm{C} p, \mathrm{MPa} \quad \mathrm{W}, \mu \mathrm{m}$

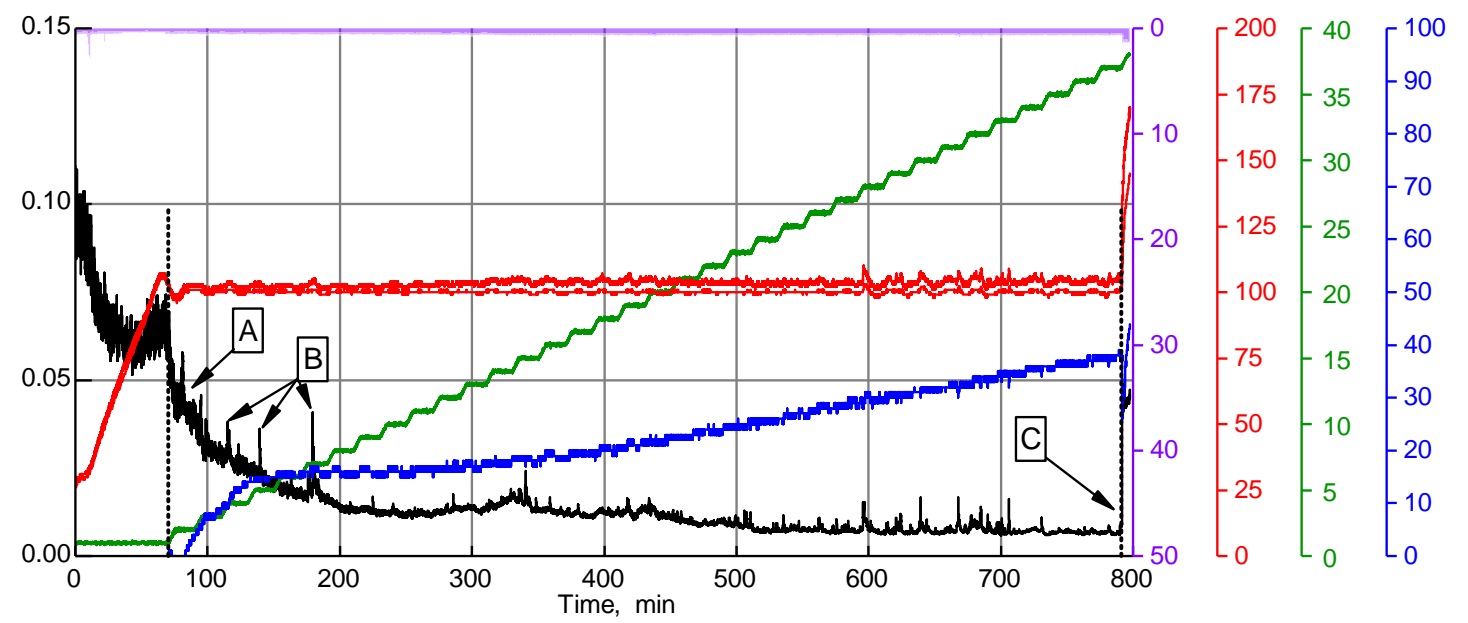

Figure 8. Result of a seizure test on casted and uncoated CuPb22Sn2. Decreasing coefficient of friction $(\mathrm{COF})(\mathrm{A})$; COF peaks after load elevation (B); shut down due to high temperature (C).

In order to identify the occurring seizure mechanism, the previously described specimen was cut into parts after evaluating the test. An SEM image of the cross-section of the specimen is depicted in Figure 9. Conspicuous is the deformed and porous microstructure close to the worn surface, a performed EDX analysis exhibits a nearly lead-free structure in point A. Similar mutations of the microstructure were found everywhere below the loaded surface. On the edge of the semicircular deformed lead, agglomerations (B) were detected. The dashed line marks the transition between the original state of the microstructure and the zone influenced by the experiment. That with of the tribologically mutated zone (mark C) was determined to be about $32 \mu \mathrm{m}$. Schouwenaars et al. were found to be similarly shaped and sized tribologically induced morphologies in a $\mathrm{CuPb}$ alloy [13]. Owing to the loss of the solid lubricating lead in the casted structure, the failure of the specimen occurred almost spontaneously.

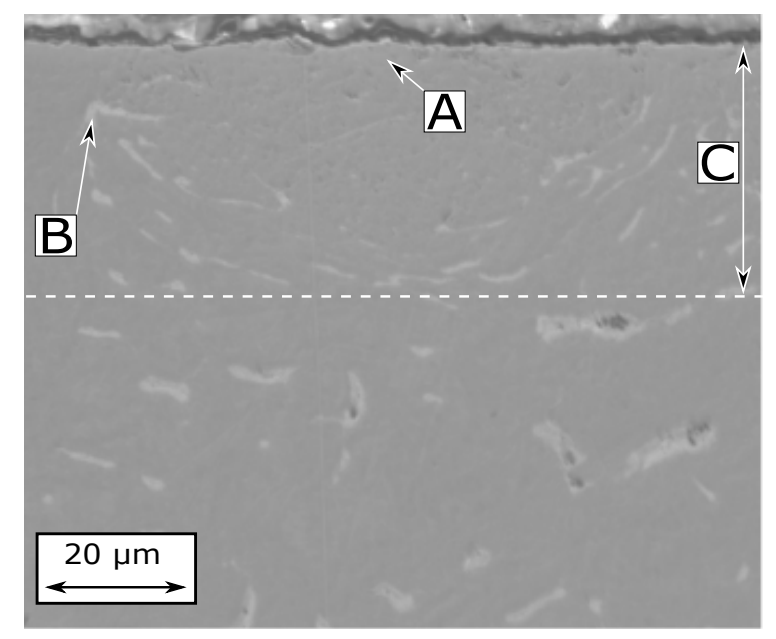

Figure 9. SEM image of the uncoated $\mathrm{CuPb} 22 \mathrm{Sn} 2$ specimen, acquired at $7.5 \mathrm{kV}$. Disturbed porous microstructure (A); distorted lead structure (B); thickness of the mutated zone (C).

\subsection{Dry-Run-Tests}

All Dry-Run-tests performed with the polymeric coating were loaded with $2 \mathrm{MPa}$ at a constant velocity after the initial lubrication of the contacting surfaces. As described previously, four drops were distributed equally on the fixed ring before the test. The differential measurement results in 
an oil quantity of $22.36 \pm 0.53 \mathrm{mg}$. In general, the reproducibility of all repeated DRTs was observed to be excellent. The characteristic behavior of the polymeric coating during a DRT is depicted in Figure 10. During the one-hour running-in phase, a minor seizure event (mark A) was observed in this test run; simultaneously, a negative peak in the CP occurs. After the temperature is stabilized, the running-in process continues. A steady state behavior is reached after additional 140 minutes (start of B); during this stage, no seizure events or temperature changes were observed. The test was stopped, as planned, after 10 hours without significant wear, thus highlighting an outstanding performance of polymeric coatings under unlubricated operational conditions.

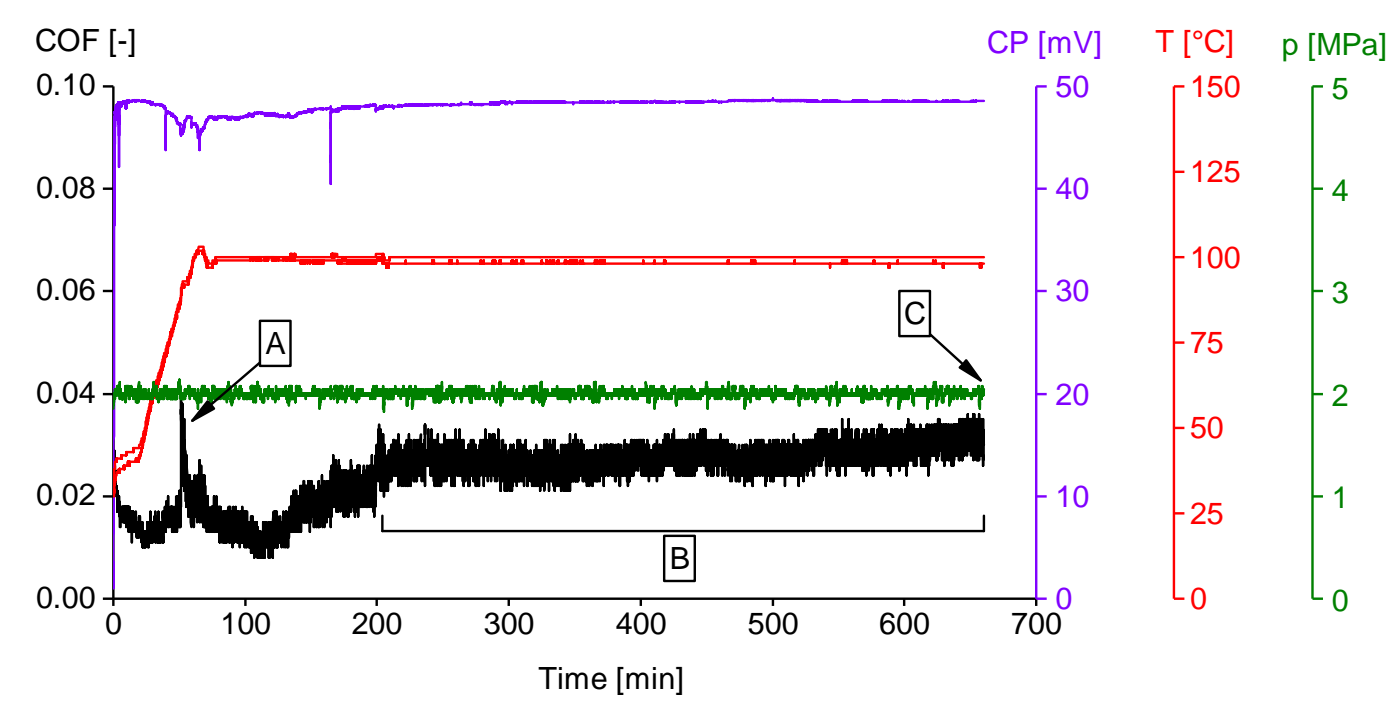

Figure 10. Result of a Dry-run-test. Seizure event during running in (A); steady state behavior (B); defined end of the test $(\mathrm{C})$.

\subsection{Start-Stop-Tests}

The characteristic friction behavior of a journal bearing with PbSn18Cu2 coating during a starting up situation is shown in Figure 11a. The load and the temperature on the JBGR is constant, while the shaft is accelerating constantly to a top speed of $1.27 \mathrm{~m} / \mathrm{s}$. Starting at low speed, the JBGR operates in boundary friction; at that time, the COF value is highest. With rising relative speed, the hydrodynamic film starts to build up slowly and the COF decreases simultaneously. The CP depicted in Figure 11b is an indicator for the state of friction; low values indicate metallic contact as they occur during boundary and mixed friction states. With increasing speed, the hydrodynamic forces are separating the surfaces of the JBGR and the shaft and the slightly conducting lubricant leads to higher transition resistance. Mixed friction occurs typically while running, while the mating surfaces are adjusting against each other. The low $\mathrm{CP}$ after 100 cycles allows for completing an incomplete running-in process or metallic particles in the lubricating gap.

The evolution of the maximum COF $\mu_{\max }$ of different SSTs is shown in Figure 12; the COF value at a relative speed of $0.05 \mathrm{~m} / \mathrm{s}$ ( $20 \mathrm{rpm}$ ) was taken for the following evaluation. The frictional evolution of the polymeric coated bearings indicates a nearly load independent behavior between $1 \mathrm{MPa}$ and $4 \mathrm{MPa}$, although the coating loaded with $4 \mathrm{MPa}$ was partially worn down to the lining material in contrast to the lower loaded bearings. Evaluating the averaged COF of all cycles at this point, a slightly higher absolute value can be seen at higher loads; this indicates a local contact between the shaft and the bearing. As the COF is still quietly stable during all test cycles, retracted coating particles of the boundary area in the contacting zone are supposed to be able to lubricate the contact during the start-up phase. The COF development of $\mathrm{PbSn} 18 \mathrm{Cu} 2$ coated bearings is much rougher compared to the polymeric bearings as well as the absolute friction values being significantly higher. After about 6500 starts and stops, the behavior changes clearly and the COF reaches a minimum at 8000 cycles; 
this phenomenon can be explained by a proceeding break through the PbSn18Cu2 layer. During the change of the behavior, it can be presumed that the COF decreases due to beneficial emergency running properties of soft lead-phases. The last 1000 cycles indicate a renewed increase of the COF, presumably caused by an already used up lead in the contacting zone.

a)

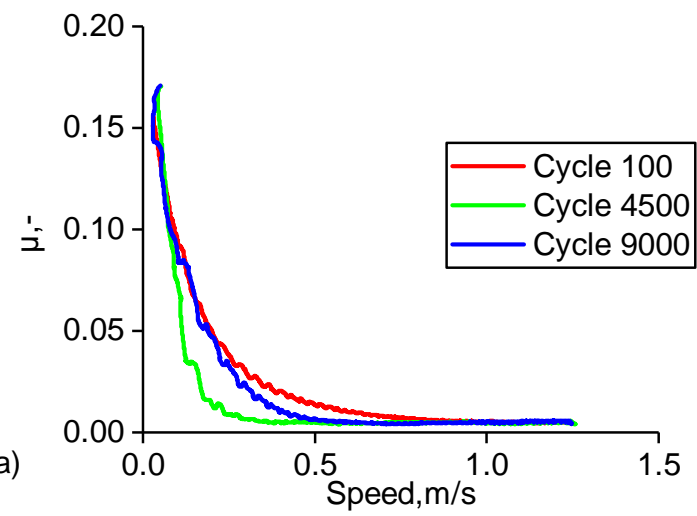

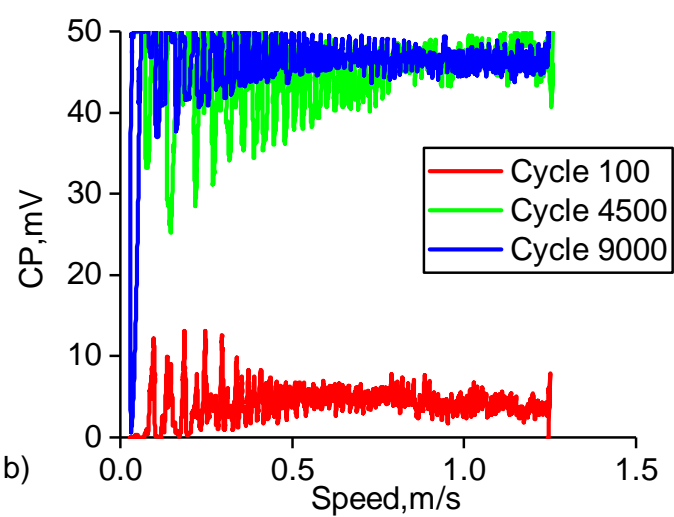

Figure 11. Characteristic Stribeck cycles of a PbSn18Cu2 coated bearing shell during a $15 \mathrm{~s}$ acceleration ramp. Speed dependent frictional behavior (a); contact potential indicating mixed and hydrodynamic friction states $(\mathbf{b})$.

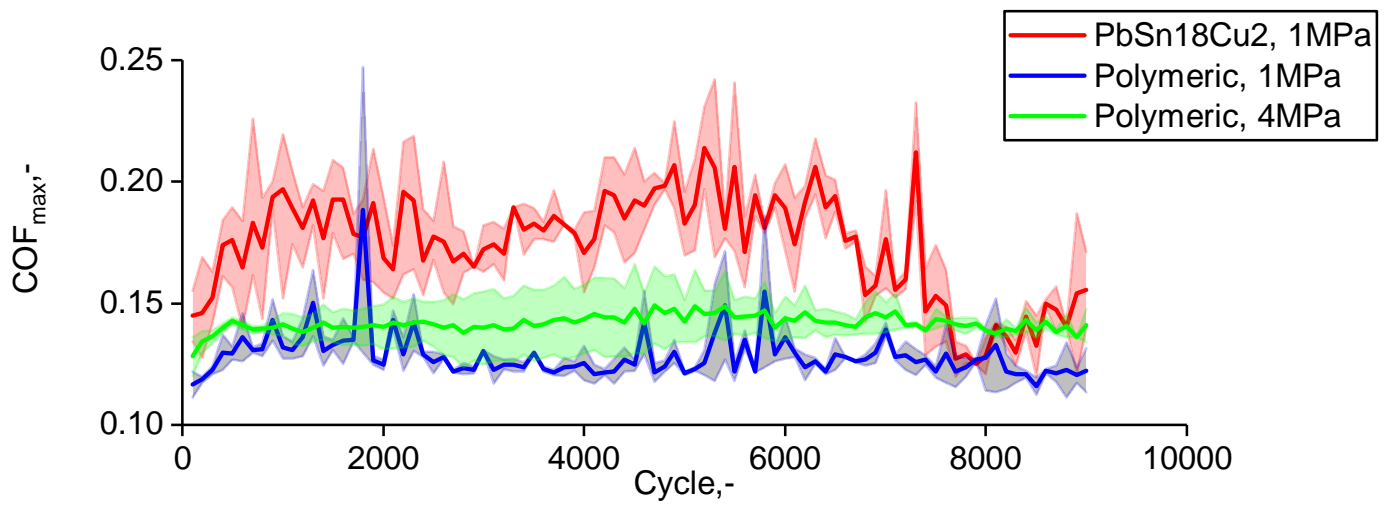

Figure 12. Evolution of the friction coefficient at very low speeds. The bold lines are the averaged COFs of identical experiments; shaded areas describe the scattering, stable behavior of the Polymeric coated JBGR; decreasing COF after 6500 starts and stops on the PbSn18Cu2 coated specimen.

\subsection{Oil-Starvation-Tests}

\subsubsection{Polymeric Coating}

The oil-starvation behavior of a polymer-coated bearing is depicted in Figure 13. During the defined running-in phase, the system operates in mixed-friction, which is indicated by a low contact potential and high friction. Once the oil was manually removed at mark $\mathbf{A}$, the test has been continued with a nominal pressure of $2 \mathrm{MPa}$ and a relative velocity of $3.77 \mathrm{~m} / \mathrm{s}$. Henceforth, the contact potential rises gradually (mark B), which is probably caused by the formation of isolating TCP tribopads from minimal oil remains. The supposed tribofilm formation takes about 30 minutes, followed by a stable behavior (mark $\mathbf{C}$ ). Beginning in point $\mathbf{D}$, the temperature increases immediately after the COF rises slightly; simultaneously, the CP drops to lower values, which is an indicator for a partial metal-to-metal contact. About 20 minutes later, the friction increases strongly (mark E), and the experiment was aborted by reaching the thermal limit of $225^{\circ} \mathrm{C}$. 


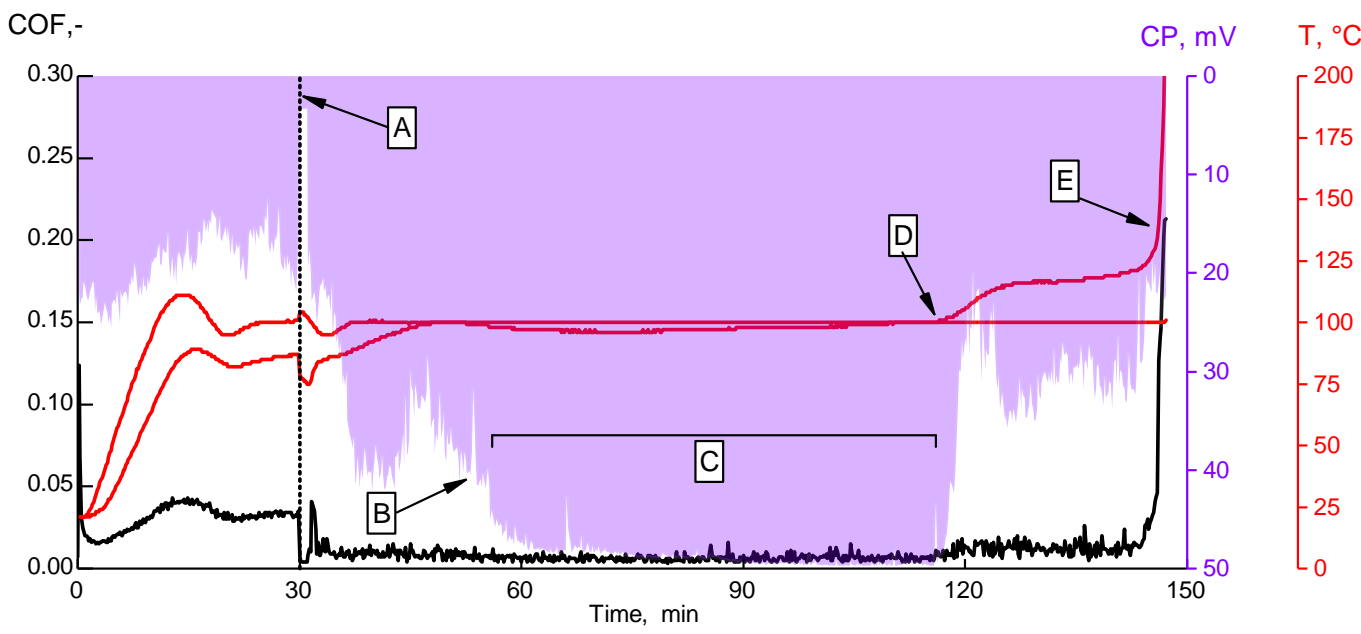

Figure 13. Result of an OST with a polymeric coating. Removal of the entire oil after running-in (A); rising contact potential (B); stable behavior (C); failure of the coating (D); abortion due to high temperature $(\mathrm{E})$.

Figure 14 depicts the corresponding bearing segment after failure. Due to high temperatures in the contacting zone, the exposed lining material shows heat-affected zones (A). Since the wear profile has its maximum in the middle of the segment, the boundary of the exposed area is still coated. Plate-shaped particles, containing lead and $\mathrm{MoS}_{2}$, are torn off in this transition area and relocated in the contacting zone (B). These particles are probably able to keep the COF low for some time, as the exposed area increasing the equilibrium is quite unstable, leading finally to the previously described thermal failure.

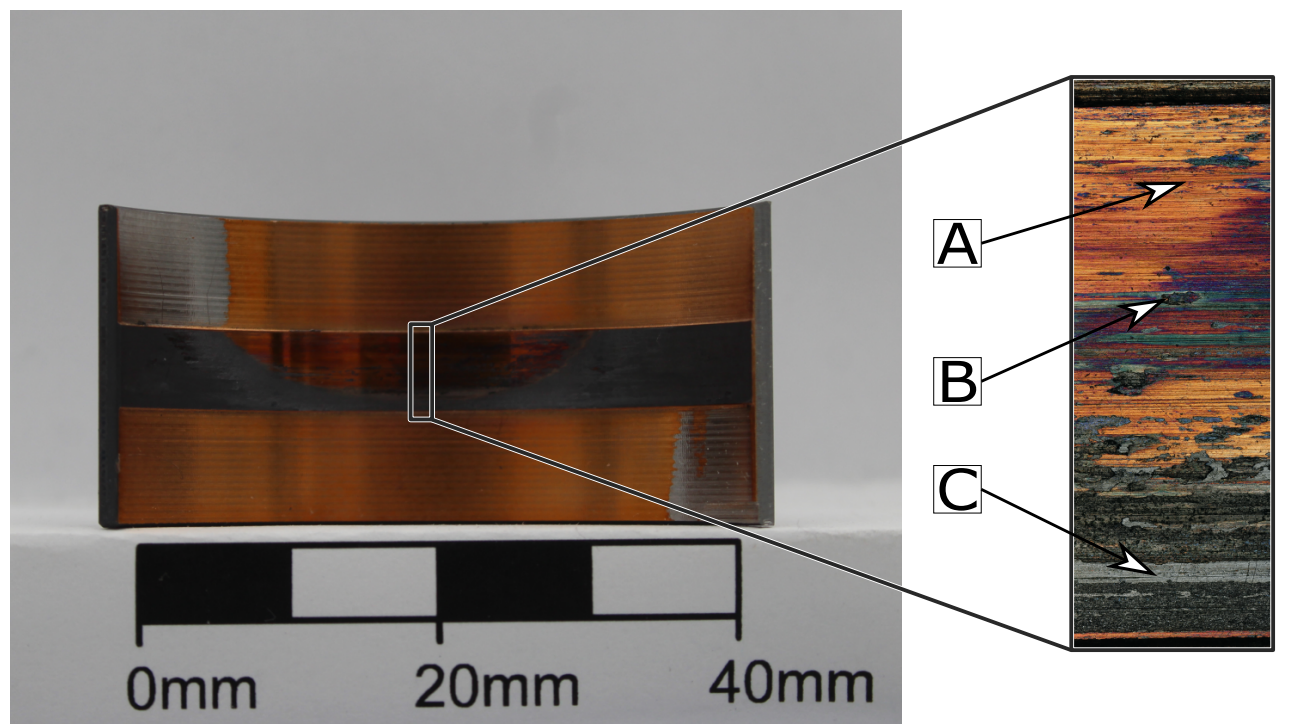

Figure 14. Bearing segment after an OST. Exposed lining material (A); particle containing and $\mathrm{MoS}_{2}$ and agglomerations of $\mathrm{Pb}(\mathrm{B})$; residual polymeric coating $(\mathrm{C})$.

\subsubsection{Electroplated Coating}

The oil-starvation behavior of a PbSn18Cu2 coated bearing shell is shown in Figure 15. After the total removal of the lubricant (mark A), the measured COF is unstable, and several peaks can be observed. Simultaneously, the temperature increases very quickly, while the $\mathrm{CP}$ indicates a high electrical resistance between the mating surfaces. In point $\mathbf{B}$, the behavior of the COF changes immediately and is stable during the steady-state zone $\mathbf{C}$. In point $\mathbf{D}$, the COF rises quickly followed by a disproportionately increasing temperature in the contact leading to the thermal limit. 


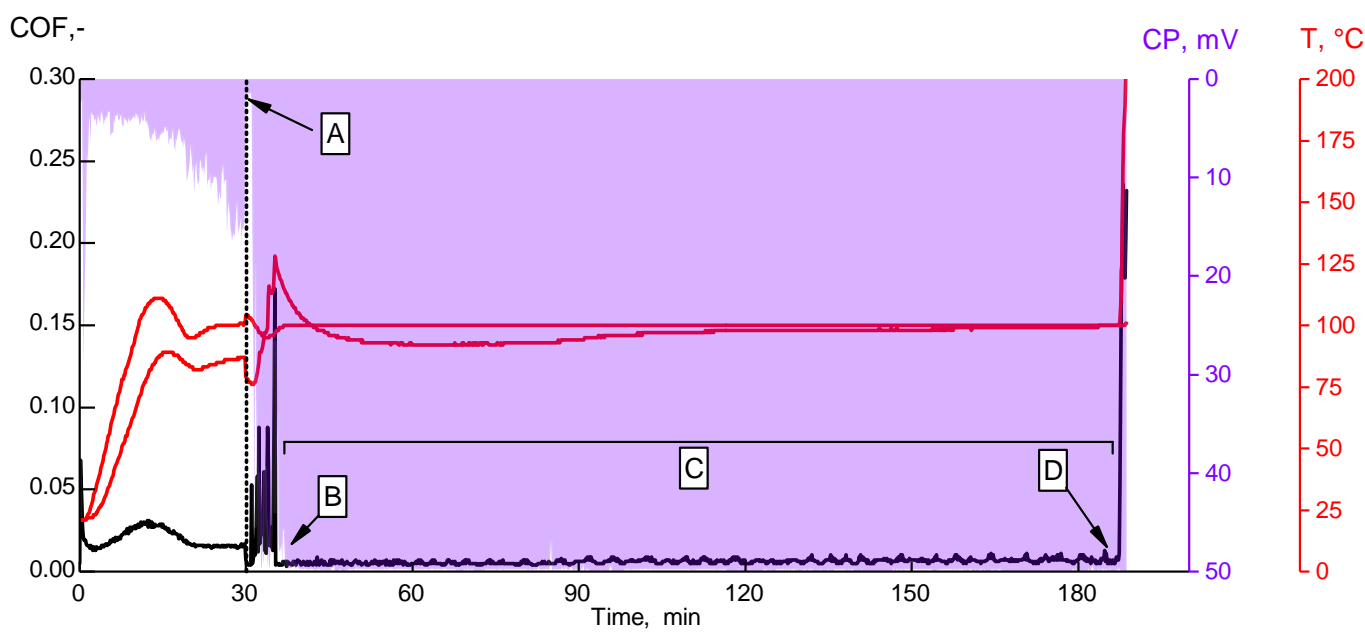

Figure 15. Result of an OST. Removal of the entire oil after running-in (A); stabilization of the COF (B); steady-state behavior (C); spontaneous failure (D).

Three identical tests were performed with this coating leading to very different residual lifetimes after the running-in procedure. The maximum temperature of $225^{\circ} \mathrm{C}$ was repeatedly reached after $8 \mathrm{~min}, 158 \mathrm{~min}$; one test did not fail during the predefined test time of $1000 \mathrm{~min}$. However, in the first minutes of the lubrication-free operation, small peaks in the COF are observed to be characteristic for this coating; see Figure 16. After the oil is removed, the contact-temperature is approximately $80^{\circ} \mathrm{C}$; the first peaks occur after no later than three minutes. It can be seen clearly that, after a COF peak, the temperature increases in correlation with the duration and the peak value of the COF. After a single peak, the temperature tends to decrease, except a further peak occurs within a short time.

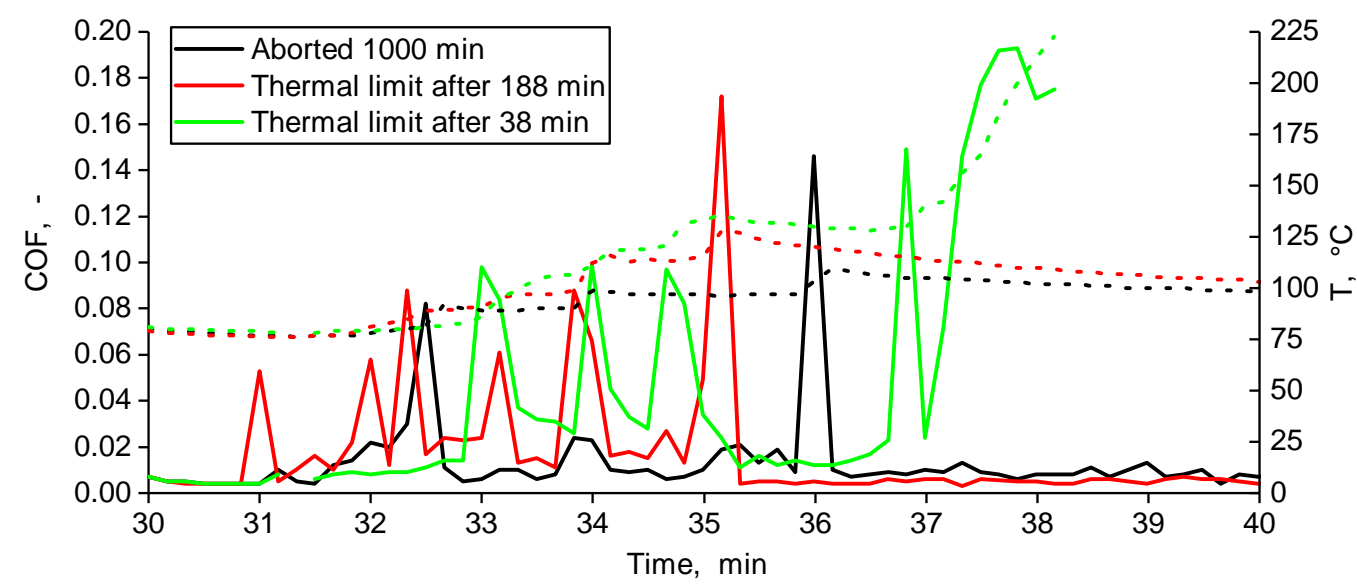

Figure 16. Early stage behavior of the COF during an OST after the lubricant is removed. Continuous lines mark the COF behavior, and dotted lines are the corresponding temperatures.

A subsequent microscopical investigation of the bearing segment that did not fail revealed a newly formed metallic layer, which was smeared all over the bearing. The ex-situ wear measurement showed that the material was worn down in the contact zone and deposited in the transition area, signed wear values indicated this theory. High shear loads in combination with elevated temperatures facilitate this ductile smearing mechanism. In Figure 17a, the magnified worn surface with the described film is shown, a cross-section perpendicular to the direction of movement is depicted in Figure 17b. 

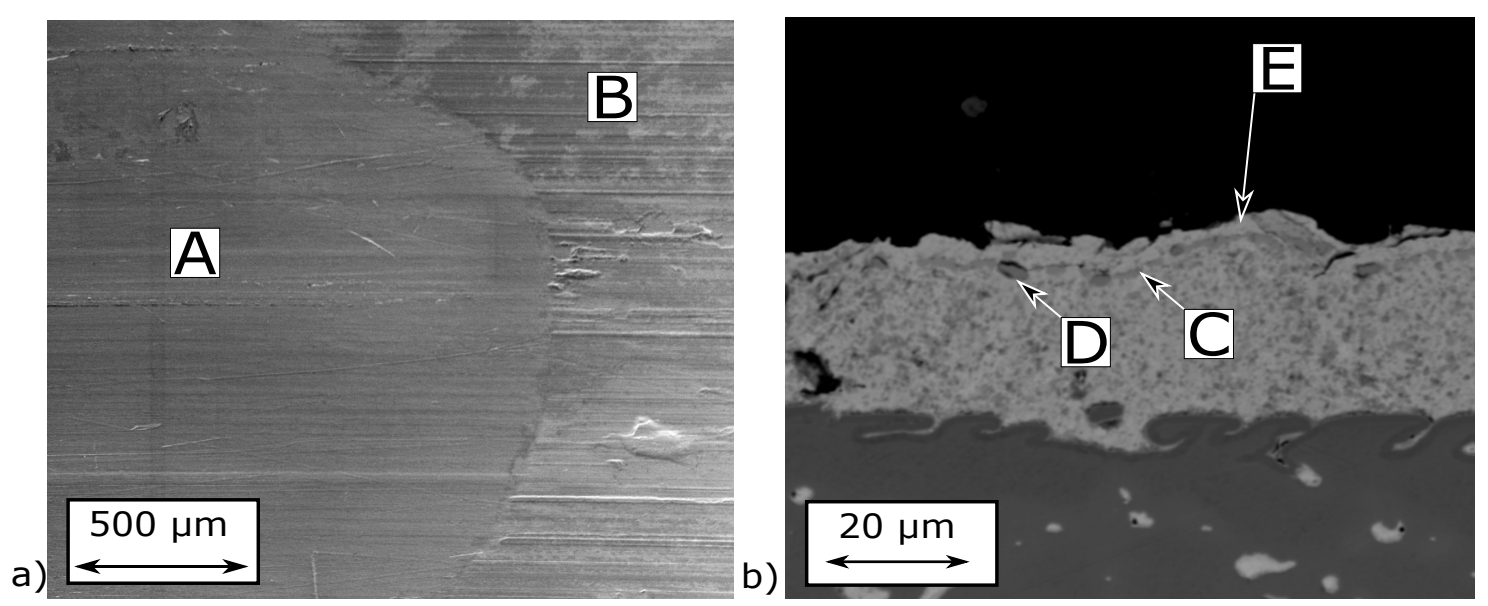

Figure 17. SEM/EDX image of the worn surface (a) and the corresponding cross-section (b). Smeared layer (A and E); coating in its initial state (B); transition zone between smeared and initial coating (C); copper particle inclusion (D).

In order to figure out the specific cause of the observed peaks and the strong scattering, an additional test was performed and stopped manually as soon as the first peak occurred. For this experiment, the first peak appeared after about three minutes. The analysis with optical microscopy revealed a fully developed smeared lead film in the contacting zone, identical to the previously observed film. Thus, it appears that these peaks are a consequence of the plastic deformation of the ductile layer material, followed by a recovery of the COF as soon as the lead is fully exposed. Furthermore, the scattering of the endurance and the repeated peaks can be explained by a weak mechanical bonding between the smeared layer and the coating in its original condition.

\section{Conclusions}

Due to an improved design for a measuring device, the repetitive accuracy of the ex-situ wear measurement was increased significantly $(<0.5 \mu \mathrm{m})$ by introducing mechanically adjustable support surfaces in combination with an angular scale for the digital micrometer gauge. Assuming an ideal osculation between the bearing segment and its fixture, the geometric dimensions of the segment can now be measured in an assembled state. Additionally, the new measuring device can be used to determine the precise bearing clearance $\Psi$ as a quality assurance method in day-to-day laboratory operation. In further studies, the measured geometric data will be used for the development of numerical wear models based on the conducted experiments.

The seizure performance revealed slightly higher friction values of the uncoated $\mathrm{CuPb} 22 \mathrm{Sn} 2$ lining material compared to the specimen with an $\mathrm{SnCuSbNi}$ overlay. The lower absolute seizure level of the coated specimen is owed to the thickness of the coating and the subsequent major seizure event on the Ni-diffusion layer.

The measures and methods to ensure a thermal stable dry-run-test under repeatable lubrication conditions are suitable to obtain comparable and measurable results. The wear-performance of the polymeric coating under these conditions showed excellent wear resistance.

Differences in the start-stop behavior between polymeric and electroplated bearings at different load levels were observed and associated damage mechanisms were identified.

A new method to examine a starved lubrication situation in journal bearings was developed and evaluated successfully on polymeric and electroplated specimens. Damage mechanisms can be observed and correlated with the measured frictional and thermal system behavior.

Author Contributions: Conceptualization, P.R., F.S., and F.G.; Data curation, P.R.; Investigation, P.R.; Methodology, P.R. and F.S.; Project administration, F.S. and F.G.; Resources, F.G. and A.E.; Supervision, F.S.; Validation, P.R.; Visualization, P.R.; Writing-original draft, P.R.; Writing-review and editing, F.S. All authors have read and agreed to the published version of the manuscript. 
Funding: This project has received funding from the Clean Sky 2 Joint Undertaking under the European Union's Horizon 2020 research and innovation program under Grant No. 785414.

Conflicts of Interest: The authors declare no conflict of interest.

\section{Abbreviations}

The following abbreviations are used in this manuscript:

VHBR Very high bypass ratio

JBGR Journal bearing

BST Bearing-segment tester

ROD Ring-on-disc

SST Start-Stop-test

DRT Dry-Run-test

ST Seizure-test

OST Oil-starvation-test

ZDDP Zincdialkyldithiophosphate

TCP Tricresylphosphate

\section{References}

1. Dik, A.; Bitén, N.; Zaccaria, V.; Aslanidou, I.; Kyprianidis, K.G. Conceptual Design of a 3-Shaft Turbofan Engine with Reduced Fuel Consumption for 2025. Energy Procedia 2017, 142, 1728-1735. [CrossRef]

2. Balli, O. Exergy modeling for evaluating sustainability level of a high by-pass turbofan engine used on commercial aircrafts. Appl. Therm. Eng. 2017, 123, 138-155. [CrossRef]

3. Bräunling, W.J. Flugzeugtriebwerke: Grundlagen, Aero-Thermodynamik, Ideale und Reale Kreisprozesse, Thermische Turbomaschinen, Komponenten, Emissionen und Systeme; Springer: Berlin/Heidelberg, Germany, 2009. [CrossRef]

4. Menezes, P.L.; Nosonovsky, M.; Ingole, S.P.; Kailas, S.V.; Lovell, M.R. Tribology for Scientists and Engineers: From Basics to Advanced Concepts; Springer: New York, NY, USA, 2013. [CrossRef]

5. Affenzeller, J.; Gläser, H. Lagerung und Schmierung von Verbrennungsmotoren; Springer: Heidelberg, Germany, 1996.

6. Summer, F.; Grün, F.; Offenbecher, M.; Taylor, S. Challenges of friction reduction of engine plain bearings-Tackling the problem with novel bearing materials. Tribol. Int. 2018, 131, 238-250. [CrossRef]

7. Summer, F.; Grün, F.; Offenbecher, M.; Taylor, S.; Lainé, E. Tribology of journal bearings: Start stop operation as life-time factor. Tribol. und Schmier. 2017, 64, 44-54.

8. Grün, F.; Gódor, I.; Gärtner, W.; Eichlseder, W. Tribological performance of thin overlays for journal bearings. Tribol. Int. 2011, 44, 1271-1280. [CrossRef]

9. Gebretsadik, D.W.; Hardell, J.; Prakash, B. Seizure behavior of some selected Pb-free engine bearing materials under lubricated condition. Tribol. Int. 2017, 111, 265-275. [CrossRef]

10. Gebretsadik, D.W.; Hardell, J.; Prakash, B. Tribological performance of tin-based overlay plated engine bearing materials. Tribol. Int. 2015, 92, 281-289. [CrossRef]

11. Bergseth, E.; Henriksson, M.; Dizdar, S.; Sellgren, U. Effects of thrust washer bearing surface characteristics on planetary gear train wear. Wear 2019, 432-433, 202933. [CrossRef]

12. Adam, A.; Prefot, M.; Wilhelm, M. Crankshaft bearings for engines with start-stop systems. MTZ Worldw. 2010, 71, 22-25. [CrossRef]

13. Schouwenaars, R.; Jacobo, V.H.; Ortiz, A. Microstructural aspects of wear in soft tribological alloys. Wear 2007, 263, 727-735. [CrossRef]

(C) 2020 by the authors. Licensee MDPI, Basel, Switzerland. This article is an open access article distributed under the terms and conditions of the Creative Commons Attribution (CC BY) license (http:/ / creativecommons.org/licenses/by/4.0/). 